\section{HUKUM, ANTARA AKIDAH DAN AKHLAK}

\section{Junaidi Lubis \\ Fakultas Syariah dan Imu Hukum UIN Suska Riau}

\section{Abstract}

Law, Between Akidah and Akhlak: Akidah and akblak have a great influence in the making of Islamic law. Islamic law which is usually called as syariah can be regarded as unification of akidah and akblak so that these three disciplines should be understood wholly because they can not be separated. Islamic law is projected to create moral people. This is because they are created by Allah in noble cratures and given some advantages which are different from other cratures. By referring Islamic law, people will have honor since it provides references to be a perfect person (insan kamil).

Keywords: Law, Akidah, and Akblak.

\section{Pendahuluan}

Akidah dan akhlak mempunyai pengaruh yang sangat besar dalam pembentukan hukum Islam. Hukum Islam yang biasa disebut syariah sepertinya merupakan penyatuan dari akidah dan akhlak sehingga ketiga ajaran Alquran ini harus dipahami bersamaan karena mempunyai hubungan saling berkait, tidak bisa dipisahkan, membulat seperti bola. Mahmud Syaltut pernah memperbincangkan persoalan ini dalam bukunya Islam Akidah dan Syariah, yang diterbitkan Dãr alQalam Mesir tahun 1966, ${ }^{1}$ namun topik intinya adalah pada Islam secara luas. Menurut beliau syariah itu ada dua, pertama peraturan yang diciptakan Tuhan, kedua pokok-pokok peraturan yang menjadi

${ }^{1}$ Buku ini telah diterjemahkan ke bahasa Indonesia tahun 1986 oleh Ir. Abdurrahman Zain, diterbitkan oleh Pustaka Amani Jakarta. kaedah untuk pembuatan peraturan dalam hidup dan kehidupan. ${ }^{2}$ Dalam istilah Alquran sendiri menurut beliau akidah disebut dengan iman, dan syariah disebut dengan amal saleh, ${ }^{3}$ beliau tidak ada mengupas tentang akhlak. Dalam buku ini pembicaraan mengenai syariah mengambil tempat yang lebih besar dari persoalan akidah karena unsur ijtihadnya yang rumit.

Akidah sebenarnya persoalan yang diterima dari wahyu, ${ }^{4}$ baik pada persoalan yang dipertanyakan akal maupun pada persoalan yang sama sekali tak terpikirkan akal. ${ }^{5}$ Sedangkan syariah membahas mengenai aturan hidup manusia kepada sesamanya, lingkungannya, dan tuhannya. Manusia tidak bisa hidup sendiri, ${ }^{6}$ harus saling berhubungan, agar keharmonisan tercipta harus diatur dengan hukum, dan hukum tujuan utamanya adalah pembentukan akhlak manusia, kesempurnaan akhlak itulah missi utama diutusnya rasul. Dengan demikian bila hukum syariah diabaikan maka telah kehilangan sebahagian besar identitas keislaman, dan jika hukum menyimpang dari keluhuran budi pekerti bukanlah hukum Islam namanya.

\section{Akidah Sebagai Landasan Hukum Ibadah}

Ketentuan syariat diletakkan dari dasar akidah yang teguh. Misalnya dalam hubungannya dengan Tuhan, semula manusia hanya

$$
\text { hlm. } 111
$$

2 Mahmud Syaltut, al-Islam `Aqidah wa Syari ah, 1966, (Mesir: Dãr al-Qalam),

${ }^{3}$ Syaltut, al-Islam, hlm. 5.

${ }^{4}$ Kebenaran yang dicari manusia dan dijawabnya sendiri dengan akalnya disebut filsafat, tingkat kebenarannya bersifat spekulatif, jika kebenaran diperoleh melalui penelitian yang seksama disebut ilmu, tingkat kebenarannya relatif. Sedangkan intuisi adalah kebenaran yang didapatkan manusia dari ilham, melalui perenungan rohaniah.

5Dengan akalnya manusia berpikir tentang alam yang teratur, lalu mencari siapa yang mengatur, lalu bertemulah dengan Tuhan, barulah asal muasal manusia dicari, pisiknya, lalu ruhnya, dari mana, akan kemana, sekarang dimana.

${ }^{6}$ Adam lebih memilih hidup di dunia meskipun berat dan penuh perjuangan asalkan ramai, dari pada hidup di surga, meskipun nikmat tetapi sepi. 
mencari tahu tentang alam, apa asal muasalnya, terbuat dari materi apa, bagaimana proses kejadiannya; lalu manusia bertanya tentang si penciptanya sendiri, siapa dia, apa keinginannya. Ketika penciptaan alam ini sempurna dan teratur, tidak berantakan, tidak tak terprediksi, dapat diketahui dan diantisipasi, menunjukkan bahwa si pencipta dan si pengatur itu satu, tidak mungkin satu perahu dua nakhoda, satu alam diatur oleh dua keinginan, tidak akan ada kehidupan di alam yang berantakan. Ini menunjukkan keesaan sang pencipta yang jenius, hebat, baik hati, wajib di sembah, dan puluhan natijah lagi yang dapat ditarik cuma dengan memikirkan satu fenomena, yaitu tentang alam dengan keteraturannya.

Sang pencipta alam dalam bahasa Arab disebut ilah, artinya tuhan, dewa, hyang, gusti, dan yang lainnya, menyembahnya disebut sembahyang. Alquran menyebut namanya Allah, dengan 98 nama lain yang menunjukkan aktifitasNya. Dalam surah al-Zumar/39: 38 dinyatakan.

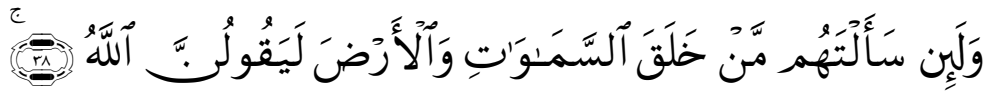

Dan sungguh jika kamu bertanya kepada mereka: "Siapakah yang menciptakan langit dan bumi?", niscaya mereka menjawab: "Allah".

Sebab hanya Allah lah yang berani mengklaim sebagai yang menurunkan hujan, menciptakan manusia, mengeluarkan yang hidup dari yang hidup, mengeluarkan yang hidup dari yang mati, menjadikan bumi sebagai hamparan, langit sebagai atap, kilat yang membelah langit, semuanya adalah sebuah keteraturan sistem yang tentu dipersiapkan oleh kekuatan dahsyat apabila dipikirkan.

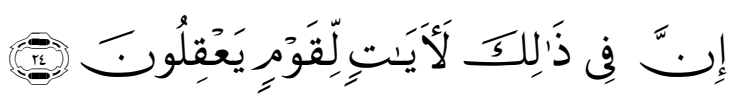

Sesungguhnya pada yang demikian itu benar-benar terdapat tanda-tanda bagi kaum yang mempergunakan akalnya.
Segala hal yang berkaitan dengan Tuhan menjadi bagian dari keyakinan, seperti tentang malaikat, kitab-kitab, rasul-rasul, hari akhirat, dan takdir. Kemudian tentang manusia, siapa dirinya, dari mana asalnya, apa tugasnya di dunia ini, akan kemana esok hari, inilah ilmu akidah. Ilmu ini kemudian dipecah lagi dengan pembicaraan yang lebih spesifik dengan nama Ilmu Kalam yang membahas tentang Alquran apakah kalam Allah yang qadim atau baharu. Di Indonesia ilmu ini dikenal dengan ilmu Sifat Dua Puluh yang membicarakan tentang sifat-sifat yang wajib bagi Allah, sifat yang mustahil, dan sifat yang jaiz. Kedua ilmu ini bertumpu pada penggunaan akal sebagai dasarnya untuk memahami keberadaan Tuhan sehingga membuahkan keyakinan yang teguh.

Dari persoalan akidah ini lahirlah pokok-pokok hukum ibadah, bahwa tuhan harus dipatuhi dan ditaati. Dalam surah al-Baqarah/2 ayat 21 Allah swt. berfirman:

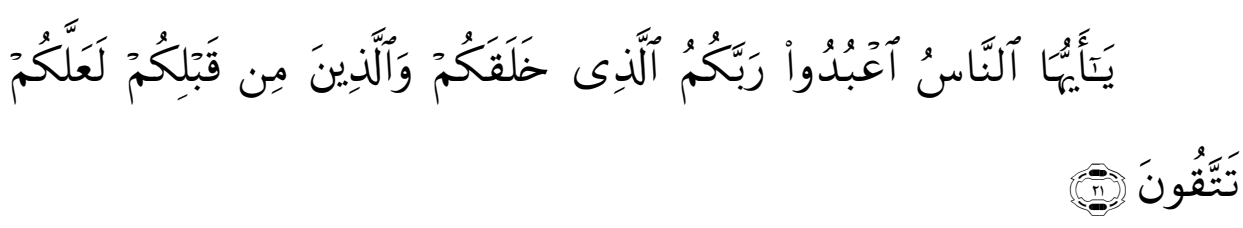

Hai manusia, sembahlah Tuhanmu yang telah menciptakanmu dan orang-orang yang sebelummu, agar kamu bertakwa,

Menurut Syaltut segala perbuatan manusia dalam rangka mendekatkan diri kepada Tuhan, atau mengagungkan dirinya yang menjadi tanda bukti keimanan kepada-Nya adalah persoalan hukum yang menempati setengah dari komposisi hukum Islam, ${ }^{7}$ sementara dalam susunan fiqh lama menempati seperempatnya, yaitu fiqh ibadah. Untuk persoalan kaifiat dan tata cara ibadah ini sangat bergantung kepada informasi wahyu yang dijelaskan oleh Sunnah, sehingga hukum ini menempati $75 \%$ lebih hukum Alquran, sisanya

\footnotetext{
${ }^{7}$ Syaltut, al-Islam, hlm. 111
} 
adalah hukum muamalah, yaitu hukum yang dikaitkan kepada hubungan yang baik antar seama manusia. ${ }^{8}$

\section{Landasan Hukum Muamalat}

Tema utama Alquran itu adalah manusia. Hukum juga untuk manusia. Hakikat diri manusia ialah materi dan immateri, yang terdiri dari unsur tanah, air, api, dan angin, sementara immaterinya disebut ruh. Menurut Descartes hakikat manusia adalah materi dan ruhani, Plato mengatakan segala hakikat berasal dari ruh, sementara Ibn Khaldun berpendapat manusia itu adalah puncak dari evolusi alam. ${ }^{9}$ Harun Nasution mengatakan manusia adalah materi dan immateri, unsur materinya adalah fisik yang mempunyai daya mendengar,melihat, dan gerak, sementara unsur immaterinya mempunyai daya fikir dan daya rasa. ${ }^{10}$

Menurut Alquran manusia adalah jasmani dan rohani, tubuh dan ruh, pisik dan nafs (nyawa, jiwa). Manusia adalah basyar, insan, dan bani | Adam.Basyar adalah makhluk jasmani, sama seperti wuhsyah (binatang), ${ }^{11}$ diciptakan dari air (21:30). Ketika manusia menghadap

${ }^{8}$ Cabang-cabang dari ilmu fiqh ibadah ini mencakup pembahasan tentang shalat dengan segala syarat dan rukunnya, puasa, zakat, dan haji dengan segala aturan dan tata caranya.

9 Pendapatnya ini mempengaruhi teori evolusi Charles Darwin yang menyatakan manusia adalah evolusi dari simpanse. Dr. Zainab al-Khaduri mengatakan bahwa dalam kitab Muqaddimah yang terbit di Eropa Ibn Khaldun menyebutkan kata qird (kera) secara langsung dalam teori evolusinya, sementara kitab yang diterbitkan di timur tengah mengganti kata qird tersebut dengan qudrah, tetapi konteksnya tidak pas (Zainab al-Khaduri, Filsafat Sejarah Ibnu Khaldun, penerbit Pustaka : Bandung 1995, hlm. 78).

${ }^{10}$ Harun Nasution, Islam Rasional (Bandung: Mizan, 1995), hlm. 37.

${ }^{11} \mathrm{Jenis}$ hewan ada dua macam, hewan berpikir dan hewan tidak berpikir. Manusia adalah hewan yang berpikir. Kata hewan adalah jenis, yang berpikir adalah diffrentia, sifat khusus yang membedakan manusia dari species hewan lainnya. Tetapi ada juga yang mendefenisikan manusia dengan defenisi yang lain, seperti hewan yang tersenyum, hewan yang menikah, dsb.
Tuhannya ia harus suci dari hadas, untuk mensucikannya dari hadas digunakan air, seperti wudhu' dan mandi junub, untuk mengingatkan manusia dari apa ia diciptakan.

Insan menunjukkan manusia dalam arti jasmaniah dan ruhaniah, ${ }^{12}$ makhluk yang mampu mengemban amanah, yang menjad alasan seluruh alam diciptakan, dan yang mendapat ruh langsung dari Allah sendiri (17:85, 78:38, 32:9, 38:72). ${ }^{13}$ Menurut Imam Nawawi alBanteni bahwa Allah adalah zat wajibul wujud (wujud utama), sedangkan manusia adalah nafilat al-wijud (wujud tambahan). ${ }^{14}$ Setiap ibadah wajib adalah hak Allah, berbeda tuntutan pengerjaannya dari yang nafilah (sunnat) sedangkan yang nafilah adalah hak wujud manusia, bernilai tambahan.

Bani Adam mengisyaratkan manusia yang sekarang adalah keturunan Adam. Gen Adam kekal sampai hari kiamat, diciptakan dari saripati air yang hina $(25: 54,32: 8,77: 20)$, awalnya dari tanah $(6: 2,32: 7$, 38:71, 37:11), berikutnya dari saripati tanah (Mu 'minun 23: 12), yaitu semua yang dimakan manusia dari tanah. Air ini disebut hina karena

12 Insan jamaknya nas, kata ini paling banyak dipakai Alquran untuk menyebut manusia, jumlahnya 241 kali, disebutkan dalam 51 surat dalam Alquran, 99 kali di ayat-ayat Makkiyah dan 142 kali disebutkan oleh ayat-ayat Madaniyah. Menurut Ibnu Manzhur kata insan diambil dari kata nus artinya bergerak, atau diambil dari kata ans, artinya mengerti, atau dari kata nisyan artinya lupa, atau dari kata uns, artinya rindu. Semua makna ini sesuai dengan karakter manusia (Ibnu Manzhur, Lisan al-Arab). Karena itu, menurut Izzuddin bin Abdi Salam manusia tidak berdosa kalau lupa sekalipun kelupaan tersebut tidak menggugurkan tanggungan (Izz al-Din Ibn Abd al-Salam, Qawãid al-Abkãm fi Mashalih al-Anam, Damaskus : Dãr al-Qalam, 1401 H.), Juz II, hlm. 1.

${ }^{13}$ Kata rub dalam Alquran dipakai untuk menyebut malaikat Jibril, yaitu ruh al-kudus, ruh al-amin, dan ruh Kami (2:87, 5:110, 16:102, 26:193, 70:4, 97:4, 19:17, 40:15, 70: 4, 2:87, 253, 97:4, 26:193, 19:17), demikian juga ruh Allah untuk menyebut Nabi Isa as. (21:91, 66:12, 4:171). Tetapi pada 16:102, 42:52 yang dimaksud ruh adalah Alquran dan pertolongan.

${ }^{14}$ Nawawi al-Jawi, Futuhat al-Madaniyyah, (Kudus : Menara Kudus), hlm. 1. 
keluar melalui saluran air kotor (86:6), namun tidak najis, karena air itulah asal tubuh manusia. ${ }^{15}$

Manusia sendiri di mata Allah adalah makhluk mulia karena kemanusiaannya, apapun statusnya, suku bangsanya, gelap terang kulitnya, juga cerdas bebal akalnya. Allah Swt. berfirman dalam Sūrah al-Isra':70 "Dan sesungguhnya telah Kami muliakan anak-anak Adam". Anak Adam dalam ayat ini maknanya adalah manusia. Dr. Muhammad Syarif Ahmad mengatakan "sekiranya kaum muslimin memperhatikan sejauh-jauhnya bagaimana Allah memberikan kemuliaan kepada manusia, yang berisi keramahan dan kemudahan serta pergaulan dalam sikap saling tolong menolong, niscaya mereka akan terdepan dalam memperbincangkan hak-hak manusia serta menetapkan kadar standarnya". ${ }^{16}$ Ungkapan ini merupakan sebuah hasil evaluasi yang sangat kuat sekali dari kenyataan bagaimana ummat Islam saat ini telah terjebak dalam primordialisme dan taassub yang parah.

Karakter manusia adalah zoon politikon, makhluk sosial, yang tidak bisa hidup sendiri, tetapi saling bergantung. Perbedaan kelamin dan keyakinan tidaklah membuat manusia keluar dari karakter bawaannya. Dalam saling ketergantungan ini manusia harus memiliki hukum yang standar, yang bisa memberikan perlindungan kepada setiap orang atas dasar kemanusiannya. Kemanusiaan dan keadilan tanpa pengecualian, adalah dua pilar utama hukum sosial Islam yang

${ }^{15}$ Dalam hukum fiqh sperma tidak najis seperti cairan lain yang keluar dari zakar, sehingga jika ia keluar tidak membatalkan wudu` tetapi jadi berhadas besa dan wajib mandi. Untuk membedakan air mani ini ulama menetapkan karakteristik seperti di surah al-Thariq ayat enam ini selain karakter alamiah lainnya, yaitu terpancar, rasanya lezat, dan diawali dari keinginan birahi.

${ }^{16}$ Muhammad Syarif Ahmad, Tajdid al-Mawqif al-Islami fi al-Figh wa al-Fiker wa al-Siyasah, (Damaskus : Dar al-Fikr, 2004), hlm. 138 begitu hidup dalam sejarah. ${ }^{17}$ Tolong menolong dalam persoalan ekonomi dan sosial ditekankan dengan sangat kuat, sebab pemanfaatan kepemilikan orang lain dengan cara yang batil adalah pengkhianatan terhadap ajaran Tuhan. Allah swt. berfirman dalam surah al-Baqarah/2: 188.

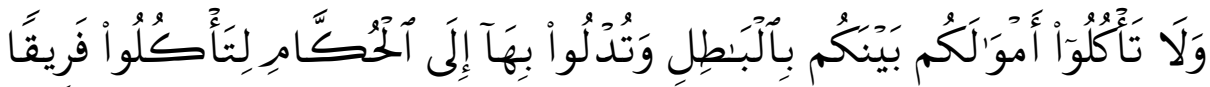

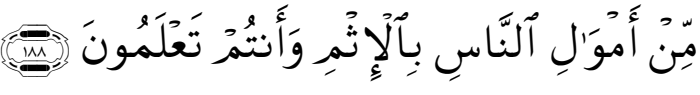

Dan janganlah sebahagian kamu memakan harta sebahagian yang lain di antara kamu dengan jalan yang bathil dan (janganlah) kamu membawa (urusan) harta itu kepada hakim, supaya kamu dapat memakan sebahagian daripada harta benda orang lain itu dengan (jalan berbuat) dosa, padahal kamu mengetahui.

Berdasarkan ini hukum memandang setiap manusia adalah sama, sebab nenek moyang mereka juga sama, yaitu Adam, sebagaimana yang dijelaskan dalam surat al-Nisa $/ 4: 4$.

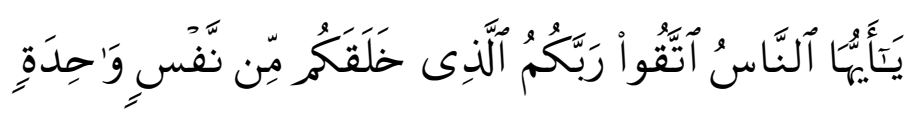

Hai sekalian manusia, bertakwalah kepada Tuhan-mu yang telah menciptakan kamu dari seorang diri.

Hukum berlaku kepada semua orang tanpa melihat strata sosial, dan identitas keturunan. Alquran mengajarkan sebelum Adam diciptakan telah ada terlebih dahulu makhluk dari api dan cahaya, yaitu jin dan malaikat. Bangsa jin adalah penghuni bumi, raja mereka bernama Azazil, berkedudukan di langit dunia yang kekuasaannya

${ }_{17}$ Misalnya bagaimana Umar dikalahkan Abu Bakar dalam perebutan anak dengan seorang nenek tua, bagaimana Ali dikalahkan dalam perebutan sebuah baju besi dengan seorang Yahudi. 
sampai ke bumi. ${ }^{18}$ Jin suka berbuat kerusakan dan menumpahkan darah maka Allah menitahkan agar Azazil menghancurkannya dengan membawa pasukan para Malaikat, sehingga hancurlah jin di muka bumi dan sisanya terlempar ke tepi air dan tepi hutan. Azazil kemudian diangkat ke surga, saat itu pula Allah menciptakan Adam, lalu yang lain diperintahkan untuk sujud. Azazil menolak (7:12), saat itu berubahlah namanya menjadi Iblis alias setan. Iblis menginginkan kedudukan khalifah ini, karena ia pernah merasakan nikmatnya kekuasaan. Allah swt. berfirman dalam surat al-Isra'/17:61

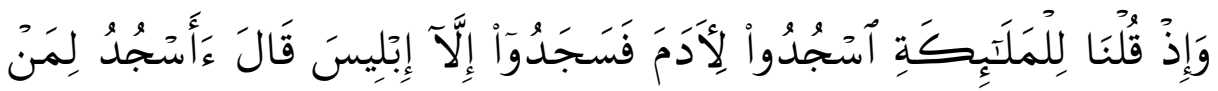

$$
\begin{aligned}
& \text { خَلَقْتَت طِينًا }
\end{aligned}
$$

Dan (ingatlah), tatkala Kami berfirman kepada para Malaikat: "Sujudlah kamu semua kepada Adam", lalu mereka sujud kecuali iblis. Dia berkata: "Apakah aku akan sujud kepada orang yang Engkau ciptakan dari tanah?"

Inilah asal mula sejarah manusia yang tak tercapai ilmu manusia sehingga menjadi kebenaran agama. Dari peristiwa ini hukum yang bernuansa etika dilahirkan, perbuatan yang buruk dicap sebagai perbuatan setan, menjadi musuh yang abadi, jika manusia tergoda bujuk rayu setan maka setan yang menang, jika mereka istiqamah berpegang pada syariat itulah kemenangan manusia.

\section{Syariah sebagai mu’jizat}

${ }^{18}$ Imam Thabari memulai kitabnya tentang raja-raja dunia dengan raja Azazil ini pertama kali (lihat Tabarī, Muhammad ibn Jarīr Abū Ja' far al-, Tärīkh al-Umam wa al-Muluk (Beirūt : Dār al-Kutub al-'Ilmiyyah, 1407).

108
Alquran adalah mu jizat nabi Muhammad saw, dan syariat adalah mu `jizat yang terbesar baginya. ${ }^{19}$ Mu jizat artinya melemahkan. Nabinabi yang mendakwakan dirinya sebagai utusan Tuhan tidak akan diterima ummat begitu saja sampai ia bisa membuktikan kebenarannya sebagai rasul. Untuk membuktikan kerasulan tersebut nabi-nabi selalu dibekali Allah dengan mu jizat sehingga manusia lemah dan tak berdaya akalnya untuk membantah. ${ }^{20}$

Menurut Ibn al-Arabi syariah itu adalah jalan Allah, hukum Allah, bukan hukum akal. Siapa yang menempuh jalan ini maka ia akan sampai kepada hakikat, dan tidak ada jalan untuk sampai kepada Allah kecuali melalui jalan ini. ${ }^{21}$ Sumber syariah adalah Alquran, lalu sunnah Rasulullah saw. Syariah juga sunnah yang baik dari kaum muslimin. ${ }^{22}$ Syariat adalah adab ilahi, Rasulullah saw adabnya telah dibina oleh Allah dengan Alquran untuk menjadi suri teladan bagi ummatnya. Adab yang menciptakan keluhuran akhlak, dan nabi saw. adalah orang yang berada dalam akhlak yang mulia (al-Qalam/68:4), menjadi kekasih Allah sebagaimana Ibrahim adalah khalilullah, dan Muhammad adalah habibullah, itulah insan kamil, manusia yang sempurna.

Hidup yang menentang syariat adalah orang yang terjebak dalam makar ilahi. Kemauan dan kemampuan untuk berpedoman kepada syariat adalah bahagian dari nikmat Allah yang amat besar, perbuatan

19 Alquran mengandung mu jizat yang bisa melemahkan orang untuk mendustakan Muhammad sebagai rasul Allah, baik dari keindahan bahasanya, informasinya tentang masa lalu, masa selama risalah, dan masa yang akan datang. Kandungannya yang berisi berbagai macam ilmu pengetahuan melahirkan teknologi ketika manusia ingin menguji kebenarannya.

$20 \mathrm{Mu}$ jizat nabi Musa adalah tongkatnya yang dapat menjadi ular besar, membelah laut merah, memukul batu hingga mengeluarkan air pada saat bani Israil kehausan, mu ¡izat nabi Isa yang bisa menyembuhkan penyakit kusta dan sopak, bisa mengobati orang buta, bahkan menghidupkan orang yang mati, dan sebagainya.

${ }^{21}$ Muhyiddin Ibnu al-Arabi, al-Fiqh. www.al-mostafa.com, hlm. 39.

${ }_{22}$ Muhyiddin Ibnu al-Arabi, al-Figh. www.al-mostafa.com 
yang menyimpang dari syariat adalah perbuatan yang mengingkari ayat-ayat Allah. Allah swt. berfirman dalam surah al-A raf/7:182-183.

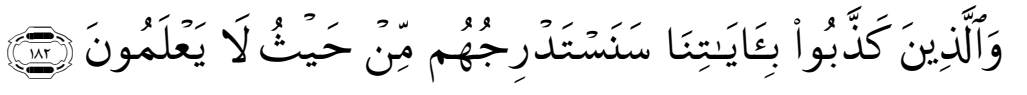

Dan orang-orang yang mendustakan ayat-ayat Kami, nanti Kami akan menarik mereka dengan berangsur-angsur (ke arah kebinasaan), dengan cara yang tidak mereka ketahui.

Apa yang diperintahkan syariat menjadi landasan kekuatan pisik dan psikis manusia. Apa yang dilarang syariat adalah racun yang mematikan. Semua ajaran syariat mengandung tujuan yang bermanfaat untuk manusia. Apabila syariat dilanggar akan menimbulkan kerusakan yang disebut dengan mafsadat. Karena itu manusia harus masuk dalam tuntutan syariat secara menyeluruh (2:208) dengan niat yang berlandaskan kepatuhan. Sebab, perbuatan manusia diukur dari niat, dan tiap orang akan mendapatkan apa yang menjadi niatnya. Inilah kaedah moralitas yang tinggi, yang kekuatannya diambil dari norma-norma agama, dan norma-norma kemanusiaan.

\section{Tujuan Penetapan Hukum Syariat}

Menurut Majallat al-Ahkam al-Adaliyyah manusia berpotensi mengekalkan atau menghancurkan bumi, sedangkan Allah menginginkan alam ini tetap kekal sampai tiba masanya berakhir, ${ }^{23}$ karena itu manusia ditugaskan Allah untuk menjaga alam agar makmur dan damai dengan hukum syariat "Dan tiadalah kami mengutus kamu, melainkan untuk (menjadi) rahmat bagi semesta alam" (al-Anbiya /21: 107). Hasan Turabi mengatakan kelestarian alam berkaitan dengan keberadaan manusia, mengekalkan alam adalah dengan cara

${ }^{23}$ Jam'iyah Majallah, Majallat al-Abkam al-Adaliyyah. T.tp. : Karkhanah Tijarat kutub, hlm. 15. mengekalkan species manusia, ${ }^{24}$ dengan cara menetapkan mereka hidup berpasangan antara laki-laki dengan perempuan, berketurunan (tawallud), berkembang biak (tanāsul), karena itu jiwa manusia harus dipimpin dengan aturan yang tepat dan efektif, sebab jiwa manusia yang rusak akan menimbulkan kerusakan di muka bumi. ${ }^{25}$

Islam mengajarkan norma-norma dasar yang universal bahwa tiap orang adalah bagian dari yang lain, karena itu manusia tidak bisa melepaskan diri dari yang lainnya, hidup berkelompok untuk mempertahankan diri, berkembang biak, dan kepentingan yang lebih luas. ${ }^{26}$ Tiap orang beda status berdasarkan fungsinya dalam kehidupan untuk saling melengkapi, mereka adalah makhluk yang lemah (4:28), harus saling melengkapi dengan sesamanya. ${ }^{27}$

Manusia itu bersaudara, karena berasal dari satu diri, yaitu Adam (4:1), dari Adam diciptakan Hawa, dari dua orang inilah asal muasal manusia. Rasulullah Saw. di Arafah bersabda "Wahai sekalian manusia, ketahuilah bahwa Tuhan kamu adalah satu, nenek moyang kamu adalah satu, ketahuilah tidak ada kelebihan bagi orang Arab atas orang Ajam, demikian pula orang Ajam atas orang Arab, tidak ada kelebihan orang berkulit merah atas orang berkulit gelap, demikian pula orang berkulit gelap atas orang berkulit merah kecuali dengan takwa kepada Allah"28

${ }^{24}$ Hasan al-Turabi, Tajdid al-Fikr al-Islämi, (Mesir : Dar al-Kutub, 1975), hlm. 75 .

${ }^{25}$ Jam'iyah Majallah, Majallat, hlm.15.

26 Makhluk hidup terdiri dari dua species, hidup dan berkembang tetapi pasif disebut dengan tumbuh-tumbuhan (nabatat). Yang hidup dan berkembang aktif disebut dengan hayawanat (hewan). Kedua peristilahan ini diambil dari istilah Arab yang telah umum dipakai dalam kosa kata Indonesia. Istilah lain dikenal juga dengan nabati dan hewani. Manusia adalah hewan yang berpikir.

${ }^{27}$ 'Tabarī, al-Jāmi', juz IV, hlm. 32.

${ }_{28}$ Ahmad b Hanbal, Musnad, (Kairo : Muassasah al-Qurthubah, tt.) Juz 5, hlm. 551 . 
Pernyataan ini merupakan kaedah yang penting untuk melihat manusia dalam persamaan, sederajat, dan seimbang. Perbedaan suku bangsa, bahasa, dan warna kulit karena perbedaan iklim dan geografis hanyalah sebagai tanda untuk mempermudah mengenali, dan mudah memberikan pertolongan (49: 13) Sesungguhnya orang yang paling mulia di sisi Allah ialah orang yang paling bertakwa. Laki-laki dan perempuan berbeda dalam kesatuan. Prestasi tiap individu dinilai lewat ketakwaan mereka dan kemampuannya megimplementasikan manfaat yang besar untuk sesamanya. Tiap orang memiliki status yang harus dijalankan dengan penuh tanggung jawab, berbagi tugas agar hidup yang dijalankan indah dan berkarakter. Rasulullah Saw. Bersabda

"Ketahuilah oleh kamu setiap kamu itu adalah pemimpin dan setiap kamu bertanggung jawab atas kepemimpinannya. Seorang amir dalam masyarakatnya adalah pemimpin dan ia akan ditanya tentang kepemimpinannya, seorang suami adalah pemimpin terhadap keluarganya dan ia akan ditanya tentang mereka, seorang isteri adalah pemimpin terhadap rumah tangga suaminya dan anak-anaknya, dan ia akan ditanya tentang mereka, seorang hamba adalah pemimpin terhadap harta tuannya dan ia akan ditanya tentang itu. Sadarilah bahwa setiap kamu adalah pemimpin dan setiap kamu akan diminta pertanggung-jawabannya tentang kepemimpinannya. ${ }^{29}$

\section{Kesimpulan}

Dari jabaran diatas dapat disimpulkan bahwa syariat tidak bisa dilepaskan dari akidah dan akhlak. Hukum syariat diproyeksikan untuk membentuk manusia yang berakhlak luhur, yang menjadi dasar kemuliaan manusia. Sebab, manusia itu dilahirkan Allah dalam bentuk mulia dan diberi Allah pengasuhan yang terbaik sehingga menjadi makhluk yang istimewa dibandingkan dengan yang lain. Berpegang kepada syariat Allah dapat memberikan kemuliaan kepada manusia

${ }^{29} \mathrm{Abi}$ ' Abd Allah Muhammad ibn Ismail al-Bukhari, al-Jami' al-Sabih, (Beirut: Dar al-Fikr), juz III, hlm. 1459. karena dalam syariat tersebut memiliki daya yang dapat membentuk manusia menjadi makhluk yang sempurna, atau insan kamil.

\section{Bibliografi}

Abi 'Abd Allah Muhammad ibn Ismail al-Bukhari, al-Jami' al-Sabih, (Beirut: Dar al-Fikr, t.th.).

Ahmad bin Hanbal, Musnad, (Kairo : Muassasah al-Qurthubah, t.th.).

Harun Nasution, Islam Rasional (Bandung: Mizan, 1995).

Hasan al-Turabi, Tajdìd al-Fiker al-Islämi, (Mesir : Dar al-Kutub, 1975).

Izz al-Din Ibn Abd al-Salam, Qawãid al-Ahkãm fi Mashalih al-Anam, (Damaskus : Dãr al-Qalam, $1401 \mathrm{H}$ ).

Jam'iyah Majallah, Majallat al-Abkam al-Adaliyyah. T.tp. : Karkhanah Tijarat kutub,

Mahmud Syaltut, al-Islam 'Aqidah wa Syari ah, (Mesir: Dãr al-Qalam, 1966).

Muhammad Syarif Ahmad, Tajdid al-Mawqif al-Islami fi al-Figh wa alFikr wa al-Siyasah, (Damaskus : Dar al-Fikr, 2004).

Nawawi al-Jawi, Futuhat al-Madaniyyah, (Kudus : Menara Kudus, t.th.).

Tabarī, Muhammad ibn Jarīr Abū Ja' far al-, Tärīkh al-Umam wa alMuluk (Beirūt : Dār al-Kutub al-'Ilmiyyah, 1407).

Zainab al-Khaduri, Filsafat Sejarah Ibnu Khaldun, Bandung: Pustaka, 1995). 